\title{
ENVELHECIMENTO E SAÚDE NAS PALAVRAS DE IDOSOS DE PORTO ALEGRE1
}

\author{
Maria Aparecida Muller Vilarino ${ }^{2}$ \\ Marta Julia Marques Lopes 3
}

\section{Resumo}

Este artigo aborda as concepções e atitudes dos idosos acerca do processo de saúde e de adoecimento no sentido de conhecer e compreender práticas preventivas em saúde e o enfrentamento de situações adversas. Foram entrevistados 30 idosos usuários do Sistema Público de Saúde de Porto Alegre. Trata-se de um estudo qualitativo que utilizou entrevistas estruturadas para coleta de dados. A análise privilegiou o conteúdo temático com definição de categorias de síntese. Os idosos que participaram são na maioria urbanos, do sexo feminino, maiores de setenta anos. Demonstraram interesse com a imagem do corpo; preocupação com a dieta alimentar; com práticas de educação adotadas para ter saúde e prevenir adversidades; mostram tendência a condutas normativas influenciadas pelo discurso profissional e pela mídia, particularmente no campo da adoção de práticas alimentares e corporais. Os idosos deste estudo consideram fundamental a manutenção de atividades físicas, intelectuais e laborais para um envelhecimento saudável. Palavras-chave: Idosos. Práticas de saúde. Prevenção.

\section{Introdução}

Este artigo aborda as práticas educativas em saúde que, freqüentemente, têm consistido em momento específico das práticas de promoção da saúde. Atribuem aos indivíduos a responsabilidade pelo seu processo de "ter saúde" e “adoecer”, cuja gravidade variará em função do maior ou menor nível de

1 Este artigo originou-se da dissertação de Mestrado da primeira autora. Trata-se de estudo híbrido onde, primeiramente, desenvolveu-se uma análise epidemiológica de tendência temporal para o levantamento histórico da morbimortalidade por pneumonias na população acima de 65 anos de Porto Alegre. Associado ao estudo epidemiológico, foi desenvolvida uma abordagem qualitativa, visando conhecer e compreender o grau de informação, as concepções e atitudes dos idosos acerca do processo saúde e adoecimento e as práticas preventivas adotadas bem como o enfrentamento de situações adversas. Essa segunda etapa é discutida neste artigo.

2 Mestre em Enfermagem. Enfermeira da Secretaria Municipal de Porto Alegre, RS. E-mail: ninica@portoweb.com.br

3 Doutora em Sociologia. Professora Titular de Saúde Comunitária da Escola de Enfermagem da Universidade Federal do Rio Grande do Sul. E-mail: marta@enf.ufrgs.br

Estud. interdiscip. envelhec., Porto Alegre, v. 13, n. 1, p. 63-77, 2008. 
informação e acesso à cultura, isto é, segundo sua capacidade de prevenir males físicos por meio de comportamentos e hábitos de higiene.

Essa premissa, durante muito tempo, norteou as práticas de educação em saúde adotadas pelos trabalhadores da área. Gastaldo (1997) denominouas de “educação em saúde tradicional” sendo desenvolvidas sob a influência da teoria da prevenção da doença, na qual a saúde era percebida como uma responsabilidade pessoal. Tradicionalmente, este tipo de educação tem sido considerada como uma prática positiva a ser integrada aos cuidados de saúde, pois veicula informações e sugere alternativas para indivíduos, famílias ou grupos em termos de prevenção à doença e de promoção da saúde.

Rosen (1994), analisando como nasceu a educação em saúde, vem corroborar a tese acima. Diz o autor, no final do século XIX, que as agências de saúde oficiais e voluntárias dos Estados Unidos viram-se envolvidas em um programa de educação que entendia que, para promover a saúde e prevenir a doença, era necessário acabar com a ignorância. Esse movimento para divulgar informação e orientações em saúde continuou durante o século XX. A chama inicial da educação em saúde nasceu do movimento antituberculose, em 1904, através de exposições sobre a doença a fim de despertar o interesse do público.

A Primeira Guerra Mundial acelerou a evolução da educação em saúde e definiu o cenário de seu crescimento principalmente em relação às doenças venéreas. Em meados do século, criou-se a Organização Comunitária para Educação em Saúde, influente até hoje no programa de Educação em Saúde nos Estados Unidos. Esta ideologia da transmissão de conhecimento através da informação para garantir uma vida saudável norteou os programas de educação em saúde no início do século em nosso país.

Durante as primeiras décadas do século XX, identifica-se que a realização de atividades de educação em saúde nos serviços básicos está impregnada de uma proposição metodológica de transmissão do conhecimento. A partir dos anos 80, a metodologia utilizada pelos profissionais da saúde assume pressupostos diferentes, adotando características problematizadoras como método de trabalho. As mudanças de então ocorreram influenciadas pelas idéias do educador Paulo Freire, particularmente na perspectiva de valorização dos múltiplos saberes envolvidos nas práticas cotidianas populares, e pelo movimento de Reforma Sanitária no Brasil, que apontou a necessidade de se repensar o processo de saúde e de adoecimento como resultantes de determinantes sociais. Neste sentido, busca-se entender a educação como instrumento de apreensão e compreensão desta realidade. 
Essas breves considerações acerca da evolução histórica e teórica do referencial sobre educação em saúde, que circula e marca a formação e as práticas institucionais de saúde no meio social, necessitam ser discutidas com base na transição demográfica e epidemiológica no Brasil. A compreensão das concepções e práticas dos idosos nesse campo exige a contextualização do fenômeno populacional e das formas de relações sociais e institucionais que o acompanham.

A partir das décadas de 40 a 60, o Brasil vivencia um processo de transição demográfica e epidemiológica. Devido à diminuição das taxas de fecundidade e mortalidade, configurou-se um aumento da presença de adultos e idosos na população. A população de zero a vinte anos, nesta e nas próximas décadas, terá taxas de crescimento reduzidas ou até negativas, ao passo que a população de 65 anos crescerá a taxas elevadas (MONTEIRO, 1995).

A transição demográfica está longe de apresentar uma evolução linear em direção a um futuro melhor, devido a uma combinação perversa de avanços para poucos e retrocesso para muitos. Os anos 90 apresentaram uma distribuição de renda mais concentrada que ao final dos anos 70, aumentando o percentual da população em extrema pobreza (SOARES, 2000).

Assim, a transição demográfica tem nítida relação com a epidemiológica. Com o aumento da população acima de 65 anos, passa-se de um quadro caracterizado pela alta prevalência de morbimortalidade por doenças infecciosas, típico da população infantil, para um quadro em que passam a predominar as doenças crônico-degenerativas, também chamadas, atualmente, de doenças de longa duração.

O país apresenta uma configuração heterogênea em sua estrutura social, econômica e demográfica e, para tanto, no planejamento de ações, há que ser considerada essa heterogeneidade, pois, onde quase não existem serviços e programas sociais para o idoso, aqueles de baixo poder aquisitivo tendem a uma pior qualidade de vida e a morrer mais cedo (VERAS, c1994).

Nesse contexto, buscou-se, através deste estudo, conhecer e compreender o grau de informação, as concepções e atitudes dos idosos acerca do processo de saúde e de adoecimento e as práticas preventivas adotadas.

\section{Método de Investigação}

Trata-se de um estudo de abordagem qualitativa, utilizando a entrevista estruturada para a coleta de dados de base sócio-epidemiológica (bairro de procedência, sexo, idade, entre outros) e de perguntas abertas, formuladas 
a partir de categorizações prévias que consideraram a problematização do estudo e a necessidade de conhecer e compreender as idéias e atitudes dos idosos acerca do tema. As entrevistas foram desenvolvidas pela própria pesquisadora em unidades de saúde. Foram selecionados, aleatoriamente, 30 idosos que freqüentam o serviço de geriatria do Centro de Saúde Santa Marta, Unidade de Saúde que pertence à rede pública de Porto Alegre. A população em estudo é usuária dos serviços públicos do Sistema Único de Saúde (SUS) exclusivamente. Está situada na faixa etária acima de 60 anos de idade. O número de idosos foi definido considerando-se estudos franceses e, particularmente, de Ghiglione e Matalon (2001), que sugerem esse número ou mais de sujeitos, como adequado à obtenção da saturação dos dados coletados.

A análise dos dados resultou na formulação de duas categorias que emergiram das questões formuladas previamente na problemática em estudo e que constaram no instrumento-guia. Além delas, após leitura exaustiva e interpretação das falas, formularam-se subcategorias que emergiram das respostas dos idosos. A primeira denominou-se o "processo de saúde e de adoecimento”. As respectivas subcategorias foram: dimensão biológica, social e bio-sócio-cultural. A segunda categoria denominou-se "cotidiano e corpo" e as subcategorias de imagem do corpo, mídia e dieta, medicalização do corpo e lazer e trabalho.

Relativamente aos procedimentos éticos, foi considerada a Resolução n. ${ }^{\circ}$ 196/96 do Conselho Nacional de Saúde para pesquisa com seres humanos (BRASIL, 1997). O projeto foi aprovado pelo Comitê de Ética em Pesquisa da Prefeitura Municipal de Porto Alegre e os idosos participantes assinaram Termo de Consentimento Informado.

\section{Resultados do Estudo}

Os idosos participantes deste estudo são oriundos de classes populares. A maioria é possuidora de imóvel próprio, sustenta-se com recursos da aposentadoria e do trabalho que alguns ainda realizam. Muitos ajudam financeiramente os familiares, cedendo seu terreno para construção de outro imóvel, entre outras contribuições, como se pode constatar em seus depoimentos.

Na distribuição da população entrevistada segundo a faixa etária (trinta idosos), identificou-se 60\% na faixa de mais de setenta anos, 30\% entre 65 e 69 anos, 10\% entre sessenta e 64 anos. Segundo o sexo, 83,3\% são do sexo feminino, e $16,7 \%$ do sexo masculino. 
Observou-se um percentual significativo de moradores do Centro de Porto Alegre devido ao acesso facilitado pela proximidade do serviço de saúde que se elegeu para realizar este estudo.

Na categoria denominada "processo de saúde e de adoecimento", analisaram-se os depoimentos do grupo em relação à pergunta "o que é saúde?”. O objetivo da pergunta foi de conhecer as representações dos idosos em relação ao que vivenciam.

A partir das respostas obtidas, categorizaram-se três dimensões distintas: a biológica, a social e a bio-sócio-cultural. Tentar-se-á, com isso, compreender a complexidade dos processos envolvidos nas próprias vivências.

A categoria denominada dimensão biológica se restringe a uma visão de cunho biologicista dos fatores influentes na saúde e foi referida por $43,3 \%$ dos idosos participantes.

A categoria dimensão social aparece em 30\% dos depoimentos dos idosos, sugerindo que a relação das representações da saúde ou da doença está diretamente relacionada com o uso social do corpo.

Denominou-se dimensão bio-sócio-cultural aquela em que o conteúdo dos depoimentos abrangia os determinantes biológicos, sociais e culturais envolvidos no tema e a complexidade conceitual que o acompanha. Estes fatores estiveram presentes em $26,7 \%$ dos depoimentos.

Na segunda categoria, denominada "cotidiano e corpo", partiu-se das questões formuladas sobre quais cuidados têm com o corpo e que atividades realizam para se manterem saudáveis. Constatou-se que os idosos foram (des)construindo imagens e adquirindo hábitos e costumes diversos, diferentes de décadas atrás. Este estudo oportunizou o desvendamento de um "novo mundo", de novas práticas entre os idosos.

A partir dessa categoria temática intitulada “cotidiano e corpo”, construíram-se as subcategorias imagem do corpo, dieta e mídia, medicalização da saúde e lazer e trabalho, as quais emergiram da análise dos depoimentos sobre os cuidados dos idosos em relação ao seu corpo e atividades que desenvolvem por julgarem importantes para sua saúde.

\section{Discussão dos Resultados}

Salienta-se que esses resultados apresentados são decorrentes de um recorte opcional de uma dissertação de mestrado elaborada entre 2000 e 2001 que, portanto, não exploram exaustivamente os temas emergentes das entrevistas e novas bibliografias. Para os leitores interessados no aprofundamento das discussões, sugere-se Vilarino (2002). 
Na categoria dimensão biológica, identificou-se preocupação com diferentes tipos de alimentos que acreditam influenciar no estado de saúde e de doença. Os exercícios físicos, como as caminhadas, são bastante comuns entre esse grupo. Também o sono e o ato de dormir bem são sinais de saúde. Encontrou-se, também, referência ao fato de que não ter doença significa, sobretudo, a "ausência de dor”, sintoma que preocupa os idosos do grupo que se detiveram a definir os processos nos limites do corpo. Essa visão biologicista é nitidamente influenciada pela predominância das práticas e políticas de saúde na sociedade brasileira, que privilegiam o modelo médico-curativo.

Tal predominância desse tipo de concepção pode ser observada em alguns depoimentos dos idosos, como: "Saúde é não sentir dor, é poder se alimentar, poder andar e dormir bem.” (Lucinda); Rosa acredita que "Saúde é não ter enfermidade grave.” Já Maria e Esmerilda relacionam saúde a cuidados com o corpo: "Saúde para mim é cuidar da alimentação, caminhar, que é o que eu faço, na nossa idade tem que se cuidar...”, “Saúde é se cuidar, fazer exercício, dar caminhadas, cuidar dos alimentos.”

Na dimensão social, a relação da saúde com o trabalho é freqüente como nos depoimentos de Laura, quando diz que "Saúde é a coisa mais importante da vida da gente, a gente tem que se cuidar para ter força de trabalhar...”, e de Lúcia: “Acho que é viver em paz e trabalhar.”

Nos depoimentos que seguem, verifica-se que os idosos do estudo, também, conseguem expressar-se de uma forma mais ampla, associando saúde e/ou doença a um estreito laço com a própria vida. Isso se expressa na fala de Verônica: "Saúde é tudo na vida, em primeiro lugar é a saúde.”; de Augusta: "Saúde é a principal coisa que existe no mundo, porque saúde é vida, é tudo na vida, saúde em primeiro lugar.”; de Roberto: “Saúde é o principal, a gente tendo saúde, tem tudo.” Já Augusto a define em sucintas e definitivas palavras: "É a felicidade."

Na seqüência das análises, denominou-se dimensão bio-sócio-cultural aquela em que o conteúdo dos depoimentos abrangia os determinantes biológicos, sociais e culturais do ser saudável e/ou adoecer. Tereza diz que "Saúde é a gente estar em paz com a vida, é muito importante, antes de tudo é gostar da gente, é gostar de viver.”, enquanto Leni associa físico e trabalho: "Saúde é não sentir nada, sentir o corpo bem, ter disposição para trabalhar.” Observa-se assim, que esses idosos constroem, ao longo de suas vidas, concepções dinâmicas e ampliadas dos eventos ligados à saúde e à doença. 
Na subcategoria imagem do corpo encontrou-se, na maioria das entrevistas em relação aos cuidados com o corpo, a preocupação com a higiene como um fator determinante em sua saúde, sendo relacionada à auto-estima e ao autocuidado. As expressões de Leni sobre os cuidados com o corpo para manter-se com saúde ilustram essa preocupação "[ . . . ] tomo banho, mesmo que esteja nevando, não fico sem tomar banho, não posso ficar sem tomar banho, renova a gente.” A imagem do corpo entre os idosos está, também, relacionada com a imagem que o outro elabora sobre seu corpo, quando demonstram uma preocupação com a limpeza e o cheiro. Nesse sentido, diz Victora (1995, p. 80) que: “Ao mesmo tempo em que o corpo adquire significado na experiência social, ele próprio é um discurso a respeito da sociedade, passível de leituras diferenciadas por diferentes agentes sociais.”

Identifica-se isso na entrevista de Alícia:

Tomo banho todos os dias, escovo os dentes, lavo o cabelo todos os dias, só mesmo se não der, troco a roupa todos os dias, ando sempre limpinha, graças a Deus. Gosto de usar um perfumezinho.

Na subcategoria dieta e mídia, observou-se entre os idosos a grande preocupação em relação ao tipo de alimentação adequada por acreditarem que a mesma influencia em sua saúde. Nesse sentido, 36,7\% de idosos relatam que comem verduras, frutas e carne branca, abolindo a carne vermelha e a gordura de sua dieta. A esse tipo de alimentação considerou-se, neste estudo, de "dieta da mídia”, já que, na última década, a sociedade foi bombardeada com preceitos normativos que condicionam a manutenção da saúde e a longevidade a mudanças no hábito alimentar. Em relação ao potencial da mídia em influenciar possíveis mudanças de hábitos alimentares, cita-se Camargo Júnior (1995, p. 19) quando afirma que

[ ... ] no caso específico do Brasil, a formulação de concepções populares acerca da saúde e da doença, está muito mais sujeita ao impacto dos meios de comunicação de massa - em especial da televisão - do que a qualquer outra fonte $[\ldots]$.

Assim, muitos idosos estão imbuídos dessa "nova cultura alimentar" induzida, podendo ser legítimo indagar-se até que ponto eles estão subme- 
tidos a um tipo de estresse, do que lhes é permitido ou interditado comer. O trecho da entrevista abaixo exemplifica, ao nível do detalhe, como hoje alguns idosos comportam-se ao se alimentarem:

[ . . . ] cuidados com a comida, a gente usa muita verdura, carne magra, o frango, eu tiro a pele, porque tenho problema de colesterol. Pressão, se eu não cuidar, ela sobe muito, eu sou hipertensa. Eu cuido da pressão com alimentação e tomo remédio também. (Alícia).

No entanto, esses condicionantes ou imperativos socio-técnicos têm limites, se for considerado que o alimento é mais que uma fonte de nutrição e está intimamente relacionado com aspectos sociais, religiosos e econômicos da vida cotidiana, sendo muito difícil modificar, por imposição, crenças e práticas alimentares. O alimento pode ser um indicador de status, como um emblema de uma identidade de grupo. Por isso, cada país, região ou cidade possui suas comidas típicas. É uma forma de agregar diversos grupos sociais (HELMAN, 1994). Um exemplo está no desafio em fazer um gaúcho típico aceitar que carne vermelha e gorda faz mal para sua saúde, visto que o churrasco é mais que um tipo de alimento: é um acontecimento social.

Identificam-se essas atitudes quando alguns idosos relatam que "saem" fora da dieta propagada como a "ideal” de comer frutas, verduras e carne branca e magra. Dizem eles:

Procuro comer mais frutas, verduras, não quer dizer que eu não como feijão, lentilha e frituras lá de vez em quando. Tenho três médicos e mais a nutricionista, que faz a dieta de verduras, frutas, coisa mais calma, menos gordura, menos sal. Mas, eu como um churrasquinho gordo. (Carlos).

Pode-se perceber, no entanto, que, normativamente, essas condutas são consideradas transgressoras de uma nova norma, de um "tipo ideal” de comportamento alimentar. As narrativas atestam esse caráter de subversão quando admitem que "saem fora da dieta lá de vez em quando".

Encontrou-se, também, nas entrevistas da maioria dos idosos, principalmente acima de oitenta anos, que sua dieta é livre. Como diz Augusta: “Quanto à alimentação, o que vem morre, não tenho nada, sou uma pessoa completamente sã. Pra mim nada faz mal, tudo é cabeça, tudo é uma questão de cabeça.” E Tereza, quando afirma: “Na alimentação eu sou relaxada, 
gosto de comer aquilo que eu gosto.” Já Roberto é mais comedido: “Como pouca comida, como de tudo, mas pouca. Não fumo e não bebo.”

A transgressão à norma parece adquirir um significado diferenciado no grupo "mais velho”. A alimentação é (re)significada, e o conceito de “comida” parece impor-se. A “comida” reflete os vínculos com a cultura alimentar de cada sujeito, e o prazer de comer aflora. Talvez seja o momento da vida de se "libertar das amarras sociais".

Na subcategoria medicalização do corpo, as pessoas confrontam-se com o mundo da tecnologia pesada, do aparato de exames laboratoriais, da rádio-imagem e dos remédios. Encontra-se uma parcela significativa da população entrevistada, 46,7\%, associando cuidados com o corpo com o uso de medicação, realização de exames e do check-up. Laura, ao referir-se aos cuidados com o corpo, diz: "Sempre vou ao médico, de seis em seis meses eu faço um check-up para melhorar a qualidade de vida. Não como gorduras, não fumo, não tomo bebidas de álcool e faço caminhada também.”

Convencionou-se denominar "medicalização da prevenção" e "medicalização do diagnóstico precoce” esse tipo de subordinação que é considerada um entrave e desencorajadora da verdadeira prevenção, levando o paciente potencial a comportar-se como um objeto, "[ . . . ] entregando-se ao médico estando ou não com saúde, transformando-se num paciente para o resto da vida.” (ILLICH, 1975, p. 65).

Identificaram-se essas características nos relatos de Érica: “Cuido do colesterol, triglicerídeos, e da comida para baixar o colesterol.”; ou de Eni: "Eu procurei um geriatra para me orientar e sigo suas orientações.” Maria traduz, também, essa dependência em relação ao aparato da medicina como forma de cuidar do corpo e de prevenir-se. Diz ela: "Cuidar do corpo é ter higiene, caminhar, boa alimentação. Eu tenho problema de colesterol, sempre tenho que fazer exame de sangue para ver com está e cuidar.”

Na subcategoria lazer e trabalho, entre as atividades realizadas para manterem-se saudáveis, observou-se que o trabalho, mesmo nessa fase de suas vidas, continua sendo algo muito importante para uma melhor qualidade de vida, e que o associam à saúde ou à doença, pois continuar trabalhando significa, para a grande maioria dos entrevistados, ter saúde. O depoimento que segue diz muito dessa nova realidade e mudança de imagem social:

Trabalho muito, até hoje, com 82 anos, eu trabalho, forro botões, faço crochê... É trabalhar, se movimentar, porque tá deitada na cama não dá, que esperança! Me levanto cedo às 7h. Durmo bem toda a noite, eu e a minha gatinha Rosinha...

Estud. interdiscip. envelhec., Porto Alegre, v. 13, n. 1, p. 63-77, 2008. 
Ainda tenho miras de durar muitos anos, eu não tenho filhos, mas tenho sobrinhos, vou nos aniversários das crianças, tudo isso a gente tem que fazer para entreter, melhorar a cabeça, o cérebro. Acho que o principal é trabalhar, se movimentar e ter amigos para conversar quando se pode. (Florinda).

Na narrativa de Augusta aparece, também, essa tendência:

Trabalho, não fico em casa deitada, trabalho oito horas por dia, pego quatro ônibus. Temos uma confeitaria, passo o dia lá. Chego em casa tarde, tomo um banho e vou dormir. Acho que isto é saúde, é vida.

Provavelmente, esta identidade de trabalhador esteja diretamente associada à identidade pessoal de como as pessoas encontram-se em várias esferas do seu cotidiano, visto que passam a maior parte de seu tempo trabalhando. Passar do mundo do trabalho para o "mundo do ócio” é algo que depende de como é feita essa transição.

Um estudo realizado na Espanha abordou a importância da preparação do idoso para a aposentadoria, e propõe que a educação permanente seja uma possibilidade de diminuir a brusca ruptura que ocorre quando se deixa a vida economicamente ativa, o que gera, em muitos, depressão (LIMON MENDIZABAL, 1990).

Assim, o trabalho aparece de diferentes formas na fala dos idosos entrevistados, seja através do trabalho formal, como fonte de renda, ou através do trabalho informal, realizado no âmbito doméstico. Nesse aspecto, identificou-se que o trabalho realizado pelas mulheres é diferente do realizado pelos homens, marcando as diferenças de gênero. Alguns idosos retratam esses aspectos das culturas de gênero:

Faço tricô, sou síndica do prédio, faço obra, contrato, faço reunião, faço bastante atividade. Esta atividade me faz bem, sempre tem alguma coisa para pensar. Tenho um irmão numa clínica, praticamente ninguém cuida dele, só eu, eu vou lá duas vezes por semana. Eu só não trabalho fora, o resto tudo que eu fazia antes, eu faço. Envelhecer depende da cabeça, né! Exercitar! (Lucrécia). 
Além do trabalho, a atividade intelectual e social é referida como algo muito importante para a manutenção da saúde. Dizem eles:

Eu trabalho com comunidade, só fico na minha casa para dormir. Eu trabalho no orçamento participativo, eu trabalho com grupos, sou voluntária, não ganho nada, só para ter uma atividade para não ficar depressiva dentro de casa, então há dez anos eu faço esse trabalho. (Laura).

Escrevo, sou aposentado, e quando estou meio nervoso, meio agitado, então eu pego a caneta e descarrego na caneta, vou escrever. Escrevo poesias, sonetos, apesar de ser humilde, tenho esse dom que Deus me deu. É a única coisa que tira minhas preocupações [ . . . ]. (João).

Outra atividade bastante freqüente entre os idosos é a caminhada. Referem-se a caminhar e dançar como algo muito importante para se manterem saudáveis:

Eu gosto de ir a baile, vou a baile, eu danço. Eu caminho uma hora por dia, sempre. Eu vou no parque, passeio, viajo. E a minha vida de casa, eu gosto de fazer a minha lida de casa, moro sozinha. Vou na casa dos filhos, às vezes cuido dos netos, é um prazer que eu tenho tido. (Neida).

Dados de pesquisa na Alemanha e em Singapura afirmam que a atividade física é um pré-requisito para um envelhecimento com sucesso. As mudanças físicas determinadas pela idade, tais como incapacidade funcional dos órgãos, modificação no sistema motor e muscular, bem como modificações nos órgãos respiratórios, estão diretamente relacionadas aos efeitos da falta de exercício. A atividade física, também, afeta o bem-estar psicológico no que diz respeito a habilidades, bem-estar pessoal, habilidades sociais e auto-estima (LEHR, 1999).

De maneira geral, verificou-se, através das entrevistas, quase que uma unanimidade em relacionar práticas saudáveis com práticas corporais, sejam caminhadas ou atividades de lazer (passeios e bailes). 


\section{Considerações Finais}

Os sujeitos deste estudo são, em síntese, essencialmente urbanos, do sexo feminino, maiores de setenta anos e usuários do SUS, visto que as entrevistas foram realizadas em um serviço público de saúde.

Neste estudo, deparou-se com um tipo de comportamento dos idosos que está substituindo aquela imagem passiva, acomodada e sedentária por um tipo de comportamento em que a manutenção da atividade física, intelectual ou laboral faz parte do cotidiano, como garantia de um envelhecimento saudável.

Em relação aos cuidados com o corpo, identificou-se preocupação com a imagem, demonstrada pelo interesse pela higiene e manutenção do peso corporal, atestando capacidade para o autocuidado e sentimentos de auto-estima singular, nesse grupo.

Verificou-se, também, preocupação freqüente com o tipo de alimento a ser consumido, com predomínio da adesão a um tipo de dieta que se denomina de “dieta da mídia”, a qual está modificando hábitos culturais e sociais. Questiona-se, a partir desses comportamentos, até que ponto esses novos hábitos estão gerando um tipo de estresse, anteriormente ausente, em relação aos alimentos selecionados como se fossem determinantes exclusivos de um estado de normalidade em saúde.

Identificou-se a influência das práticas de educação em saúde de tendência normatizadora e normalizadora na tentativa de regrar e disciplinar a vida e os corpos das pessoas nos aspectos relacionados às práticas de prevenção em saúde. Essa tendência enfrenta a "resistência” de alguns sujeitos que, nem sempre, adotam o que é tido como "verdade” em seu cotidiano.

Outro aspecto evidente nas práticas preventivas adotadas pelo grupo é a dependência ao aparato da medicina através do check-up, da dependência aos fármacos ou do seguimento das orientações médicas como rotina de vida. Fica evidente a prevalência do modelo médico-curativo que permeia os serviços de saúde, constituindo como senso comum a medicalização da prevenção.

Por outro lado, emergiu das análises a importância do trabalho. Analisou-se o quanto o trabalho está intimamente ligado à identidade de cada um, seja o trabalho formal ou informal, que ainda faz parte do mundo desses idosos e funciona, segundo eles próprios, como uma “fonte de vida”. Deixar de trabalhar significa perda de identidade e, conseqüentemente, em certa medida, desistência de lutar pela vida. 
A manutenção constante de práticas corporais e intelectuais (atividade física) também foi apontada por esse grupo de idosos como algo muito importante e mesmo decisivo para o envelhecimento saudável.

Frente a esses resultados, verificou-se a necessidade da implementação de políticas públicas que promovam atividades de lazer, de esportes, educacionais e laborais dirigidas aos idosos, as quais estariam proporcionando inclusão social, práticas de promoção à saúde e garantindo um envelhecimento com qualidade de vida.

\title{
AGING AND HEALTH IN THE WORDS OF AGED OF PORTO ALEGRE
}

\begin{abstract}
This article originated from the mestrado dissertação of of the first author. The chapter was approached qualitative, in which the conceptions and attitudes of aged concerning the process the health-illness had been investigated, to know and to understand the degree of information of the practical preventive in health adopted, for a group of 30 aged users of the Public System of Health, in Porto Alegre. The used methodology was a study of qualitative boarding, used it interview structuralized for collection of data, became fullfilled it analysis of thematic content, for the attainment of the results. Aged that they had participated of the this study, they were essentially urban, feminine, biggest ones of seventy years, had demonstrated interest with the image of the body, concern with the alimentary diet, the practical ones of education in health adopted in health, had been of normatizadora and normalizadora trend. The aged ones consider that the maintenance of physical activities is basic, intellectual and labor for a healthful aging. Keywords: Aged. Healthcare practices. Prevention.
\end{abstract}

\section{REFERÊNCIAS}

BRASIL. Ministério da Saúde. Conselho Nacional de Saúde. Resolução 196, de 10 de outubro de 1996. Diretrizes e normas regulamentadoras de pesquisa envolvendo seres humanos. Brasília, DF, 1997. 
CAMARGO JÚNIOR, Kenneth Rochel. Medicina, Medicalização e Produção Simbólica. In: PITTA, Aurea M. da Rocha (Org.). Saúde e Comunicação: visibilidades e silêncios. São Paulo: Hucitec, 1995. P. 13-24.

GASTALDO, Denise. É a Educação em Saúde “Saudável”? Educação \& Realidade, Porto Alegre, v. 22, n. 1, p. 147-168, jan./jun. 1997.

GHIGLIONE, Rodolphe; MATALON, Benjamin. O Inquérito: teoria e prática. 4. ed. Oeiras: Celta, 2001.

HELMAN, Cecil G. Cultura, Saúde e Doença. 2. ed. Porto Alegre: Artes Médicas, 1994.

ILLICH, Ivan. A Expropriação da Saúde: nêmesis da Medicina. Rio de Janeiro: Nova Fronteira, 1975.

LEHR, Ursula. A Revolução da Longevidade: impacto na sociedade, na família e no indivíduo. Estudos Interdisciplinares sobre o Envelhecimento, Porto Alegre, v. 1, p. 7-35, 1999.

LIMON MENDIZABAL, Maria Rosario. Reflexiones sobre la Educación en la Tercera Edad. Revista de Educación, Madrid, n. 291, p. 225-251, enero/ abr. 1990.

MONTEIRO, Carlos Augusto. Velhos e Novos Males da Saúde no Brasil: a evolução do país e de suas doenças. São Paulo: Hucitec, 1995. (Saúde em Debate, 91).

ROSEN, George. Uma História da Saúde Pública. São Paulo: Hucitec, 1994.

SOARES, Laura Tavares Ribeiro. América Latina: transição epidemiológica ou retrocesso social. Acta Paulista de Enfermagem, São Paulo, v. 13, n. esp., p. 55-76, 2000. Parte 1.

VERAS, Renato Peixoto. País Jovem com Cabelos Brancos: a saúde do idoso no Brasil. 2. ed. Rio de Janeiro: Relume-Dumará, c1994. 
VICTORA, Ceres Gomes. As Imagens do Corpo: representações do aparelho reprodutor feminino e reapropriação dos modelos médicos. In: LEAL, Ondina Maria Fachel (Org.). Corpo e Significado: ensaios de antropologia social. Porto Alegre: Editora da UFRGS, 1995. P. 77-88.

VILARINO, Maria Aparecido Müller. A (Re)Volta da Vacina: eficácia e credibilidade social da vacinação contra influenza entre idosos de Porto Alegre. 2002. 97 f. Dissertação (Mestrado em Enfermagem) - Escola de Enfermagem, Universidade Federal do Rio Grande do Sul, Porto Alegre, 2002.

Recebido em: 10-10-2007

$1^{a}$ revisão: 01-04-2008

$2^{a}$ revisão: 06-06-2008

Aceite final: 11-06-2008 